\title{
Quality of care and health-related quality of life of climacteric stage women cared for in family medicine clinics in Mexico
}

Svetlana Vladislavovna Doubova Dubova ${ }^{1 *}$, Sergio Flores-Hernández², Leticia Rodriguez-Aguilar', Ricardo Pérez-Cuevas ${ }^{1}$

\begin{abstract}
Objectives: 1) To design and validate indicators to measure the quality of the process of care that climacteric stage women receive in family medicine clinics (FMC). 2) To assess the quality of care that climacteric stage women receive in FMC. 3) To determine the association between quality of care and health-related quality of life (HR-QoL) among climacteric stage women.

Methods: The study had two phases: I. Design and validation of indicators to measure the quality of care process by using the RAND/UCLA Appropriateness Method. II. Evaluation of the quality of care and its association with HRQoL through a cross-sectional study conducted in two FMC located in Mexico City that included 410 climacteric stage women. The quality of care was measured by estimating the percentage of recommended care received (PRCR) by climacteric stage women in three process components: health promotion, screening, and treatment. The HR-QoL was measured using the Cervantes scale (0-155). The association between quality of care and HR-QoL was estimated through multiple linear regression analysis.

Results: The lowest mean of PRCR was for the health promotion component (24.1\%) and the highest for the treatment component (86.6\%). The mean of HR-QoL was 50.1 points. The regression analysis showed that in the treatment component, for every 10 additional points of the PRCR, the global HR-QoL improved 2.8 points on the Cervantes scale (coefficient $-0.28, \mathrm{P}<0.0001$ ).

Conclusion: The indicators to measure quality of care for climacteric stage women are applicable and feasible in family medicine settings. There is a positive association between the quality of the treatment component and HRQoL; this would encourage interventions to improve quality of care for climacteric stage women.
\end{abstract}

\section{Introduction}

The climacteric stage is the transition from the reproductive to the non-reproductive period during the life of women [1], and comprises 2-8 years before and after menopause [2]. During the climacteric stage, the decline in ovarian hormones and aging contribute to the appearance of climacteric symptoms, decrease in bone mass density, and increase in chronic diseases [2].

This complex scenario may negatively affect the woman's health-related quality of life (HR-QoL) [3] and

\footnotetext{
* Correspondence: svetlana.doubova@imss.gob.mx

'Unidad de Investigación Epidemiológica y Servicios de Salud Centro Médico Nacional Siglo XXI, Instituto Mexicano del Seguro Social, México DF, México
}

(c) 2010 Doubova (Dubova) et al; licensee BioMed Central Ltd. This is an Open Access article distributed under the terms of the Creative Commons Attribution License (http://creativecommons.org/licenses/by/2.0), which permits unrestricted use, distribution, and reproduction in any medium, provided the original work is properly cited.

increases her need for health services [4]. The definition of HR-QoL is as follows: "the perception of a person about his/her physical and psychological health, level of independence and social relationships" [5]. HR-QoL is a proxy for health status, and an outcome variable of epidemiological, clinical, and health systems research studies; it is also an independent predictor for the analysis of the use and cost of health services [6,7].

Measuring the HR-QoL is relevant during the climacteric stage. Hot flashes and sweating can cause anxiety, social isolation, and difficulties at work, which in turn affects HR-QoL $[3,8]$. Factors such as older age, lack of partner and/or children, unfavorable socioeconomic conditions, low social support, presence of chronic 
diseases, obesity, and unhealthy lifestyles are associated with low HR-QoL as well [9-11].

Reports from clinical trials have shown that hormone therapy (HT) decreases climacteric symptoms and has a positive effect on HR-QoL $[9,12,13]$. However, there are no studies aimed at measuring the quality of health care that climacteric stage women receive and its relationship with HR-QoL.

The quality of health care is a multidimensional concept that includes "the degree to which health services for individuals and populations increase the likelihood of desired health outcomes and are consistent with current professional knowledge" [14]. The approach to assess quality should address either individual or population perspectives; in both, it is appropriate to include in the assessment any of the usual three dimensions: structure, process, and outcomes [15].

Process of care is the actual provision and reception of care through interactions between users and providers. At the individual level, measuring the quality of the process of care through indicators is a robust approach [16]. The indicators can measure different components of the process of care, and should be constructed upon standards of care that follow systematic methods based on scientific evidence and/or expert opinion, and should be replicable. The indicators allow valid judgments of the quality of care to be reached and, although they do not provide definitive answers, allow the identification of potential problems during the provision of health care [17].

The growing number of climacteric stage women and the increasing body of knowledge about the complexity of their health needs are raising new requirements for health services.

Health care for climacteric stage women should be comprehensive. This comprises the provision of hormone therapy (HT) when appropriate for climacteric symptoms, and should include counseling about climacteric and menopause, promotion of a healthy lifestyle, and screening, diagnosis, and treatment of chronic diseases. These components must fulfill standards of care that can meet the expectation to achieve a positive effect on the health status and HR-QoL of women.

To build up the evidence on this topic, this study had the following objectives: 1) To design and validate indicators to measure the quality of the process of care that climacteric stage women receive in family medicine clinics. 2) To assess the quality of care that climacteric stage women receive in family medicine clinics. 3) To determine the association between quality of care and healthrelated quality of life among climacteric stage women.

\section{Methods}

The study was conducted in two phases: I. Design and validation of indicators to measure the quality of care that climacteric stage women receive in family medicine clinics. II. Assessment of the quality of care and of its association with HR-QoL in climacteric stage women.

\section{Phase I}

To design and validate indicators, we used the modified version of the RAND/UCLA Appropriateness Method [18]. This method combines expert opinion and systematic literature review of scientific evidence [19].

The method comprised the following activities:

i) Systematic search and review of the literature to collect scientific evidence regarding the care process activities that climacteric stage women should receive at the family medicine clinic. The databases of Medline, Ovid, Cochrane Library, National Institute for Clinical Excellence, and World Health Organization covering the period 1990-2008 were consulted. The entries for the search were "climacteric" and/or "menopausal" and/or "postmenopausal women," "quality of care indicators" and "guidelines," and "family medicine clinics" or "primary care services."

We identified five systematic reviews, four meta-analyses, and 128 publications that included clinical practice guidelines, clinical trials, and cohort, case-control and cross-sectional studies relevant to answering the scientific question. The criteria of Saslow were used to scrutinize and classify the literature according to the study type and the level of evidence [20].

The systematic literature review allowed the identification of three key components of the process delivered to climacteric stage women: health promotion, screening, and treatment. Within each component, the critical activities to achieve a positive effect on women's health were identified. The research group proposed 16 indicators to evaluate the quality of the process of care

ii) An expert panel was integrated by two gynecologists who specialized in climacteric and menopause, two health systems researchers, and two family doctors. All had proven experience in clinical and health system research, and in the development of clinical guidelines/ indicators. Each panelist received by e-mail the information about the study objectives, a list of proposed indicators, and the relevant literature. Panelists were asked to validate the indicators by assigning a value from 1 to 9 $(1=$ definitely not valid and $9=$ definitely valid $)$. The classification of the validity of the indicators followed the criteria of Shekelle [21]. The panelists had to use these criteria to individually rate the proposed indicators. To consider an indicator valid, the median panel rating was set to $\geq 7$. This decision was in accordance with a published study [21].

After two e-mail rounds of ranking, one vis-à-vis meeting, and a review for coherence and content validity, a final set of 14 indicators was integrated (Table 1). 
Table 1 Indicators of quality of care that climacteric stage women receive in family medicine clinics

\begin{tabular}{|c|c|}
\hline Indicator & Formula \\
\hline \multicolumn{2}{|l|}{ I. Health promotion } \\
\hline $\begin{array}{l}\text { 1. Counseling about climacteric stage and menopause in the last } \\
\text { year }\end{array}$ & $\begin{array}{l}\text { Number of climacteric stage women who received counseling about climacteric } \\
\text { stage, menopause and self-care related activities by the family doctor or other } \\
\text { health professionals, in the last year/Total number of women in the sample } \times 100\end{array}$ \\
\hline 2. Nutritional counseling in the last year & $\begin{array}{l}\text { Number of climacteric stage women who received nutritional counseling by the } \\
\text { family doctor or other health professionals, in the last year/Total number of } \\
\text { women in the sample } \times 100\end{array}$ \\
\hline 3. Advice on regular leisure time physical activity in the last year & $\begin{array}{l}\text { Number of climacteric stage women who received advice on regular leisure time } \\
\text { physical activity by the family doctor or other health professionals, in the last } \\
\text { year/Total number of women in the sample } \times 100\end{array}$ \\
\hline 4. Smoke cessation counseling in the last year & $\begin{array}{l}\text { Number of current smokers climacteric stage women who received smoke } \\
\text { cessation counseling by the family doctor or other health professionals, in the last } \\
\text { year/Total number of actively smoking women in the sample } \times 100\end{array}$ \\
\hline \multicolumn{2}{|l|}{ II. Screening } \\
\hline 1. Deliberate search of climacteric symptoms in the last year & $\begin{array}{l}\text { Number of climacteric stage women who were asked by the family doctor about } \\
\text { climacteric symptoms in the last year/Total number of women in the sample } \times \\
100\end{array}$ \\
\hline $\begin{array}{l}\text { 2. Screening for overweight and obesity by calculating the body } \\
\text { mass index (BMI) in the last year }\end{array}$ & $\begin{array}{l}\text { Number of climacteric stage women who received overweight and obesity } \\
\text { screening through the BMl calculation by the family doctor in the last year/Total } \\
\text { number of women in the sample } \times 100\end{array}$ \\
\hline $\begin{array}{l}\text { 3. Screening for hypertension by measuring the systolic and } \\
\text { diastolic blood pressure in the last year }\end{array}$ & $\begin{array}{l}\text { Number of climacteric stage women that received hypertension screening } \\
\text { through measuring the systolic and diastolic blood pressure by the family doctor } \\
\text { or other health professionals, in the last year/Total number of women in the } \\
\text { sample } \times 100\end{array}$ \\
\hline $\begin{array}{l}\text { 4. Screening for diabetes by measuring fasting plasma glucose in } \\
\text { the last year }\end{array}$ & $\begin{array}{l}\text { Number of climacteric stage women who received diabetes screening through } \\
\text { fasting plasma glucose measurement, in the last year/Total number of women in } \\
\text { the sample } \times 100\end{array}$ \\
\hline $\begin{array}{l}\text { 5. Screening for breast cancer through mammography in the } \\
\text { last } 2 \text { years }\end{array}$ & $\begin{array}{l}\text { Number of climacteric stage women who received breast cancer screening } \\
\text { through mammography, in the last } 2 \text { years/Total number of women in the } \\
\text { sample } \times 100\end{array}$ \\
\hline $\begin{array}{l}\text { 6. Screening for cervical cancer through Pap test in the last } 3 \\
\text { years in women without a history of total hysterectomy }\end{array}$ & $\begin{array}{l}\text { Number of climacteric stage women without a history of total hysterectomy for } \\
\text { benign disease who received cervical cancer screening through Pap test, in the } \\
\text { last } 3 \text { years/Total number of women in the sample without a history of total } \\
\text { hysterectomy } \times 100\end{array}$ \\
\hline \multicolumn{2}{|l|}{ III. Treatment } \\
\hline \multirow[t]{2}{*}{ 1. Appropriate indication of oral hormone therapy $(\mathrm{HT})$} & $\begin{array}{l}\text { a) Number of women with moderate or severe vasomotor symptoms } 7 / \text { day } \geq \text { (at } \\
\text { the time of the interview or the time to start oral HT) and without HT } \\
\text { contraindications, who receive oral HT }\end{array}$ \\
\hline & $\begin{array}{l}\text { b) Number of women with moderate or severe vasomotor symptoms }<7 / \text { day (at } \\
\text { the time of the interview or the time to start oral HT), or with mild symptoms or } \\
\text { without vasomotor symptoms who do not receive oral HT/Total number of } \\
\text { women in the sample } \times 100\end{array}$ \\
\hline \multirow[t]{2}{*}{ 2. Appropriate indication of vaginal $H T$} & $\begin{array}{l}\text { a) Number of women with moderate or severe vaginal atrophy symptoms and } \\
\text { without oral HT who receive vaginal HT }\end{array}$ \\
\hline & $\begin{array}{l}\text { b) the number of women without moderate to severe vaginal atrophy symptoms } \\
\text { or with oral HT who do not receive vaginal HT/Total number of women in the } \\
\text { sample } \times 100\end{array}$ \\
\hline 3. Appropriate prescription of oral HT & $\begin{array}{l}\text { Number of women receiving oral } H T \text { prescription appropriately according to the } \\
\text { drug scheme, dose, schedule and duration of the treatment/Total number of } \\
\text { women in the sample receiving oral HT } \times 100\end{array}$ \\
\hline 4. Information on risks and benefits of oral HT & $\begin{array}{l}\text { Number of women who were prescribed oral } \mathrm{HT} \text { and who received information } \\
\text { about its purpose, benefits and risks/Total number of women in the sample } \\
\text { receiving oral } \mathrm{HT} \times 100\end{array}$ \\
\hline
\end{tabular}




\section{Phase II}

From November 2008 to March 2009, we conducted a cross-sectional study in two Instituto Mexicano del Seguro Social (IMSS) family medicine clinics (FMC) located in Mexico City. The FMC were randomly selected from the list of existing FMC in Mexico City. One clinic was in the south of the city and the other in the north. Both clinics had similar characteristics, such as the number of examining rooms and people covered.

The IMSS is a social security system for workers in the formal market; $\sim 48$ million Mexicans are affiliated with this institution [22].

The study population was women in climacteric stage aged 45-59 years attending the FMC. To identify these women we used the definition of the "Clinical Practice Guideline on the Menopause and Postmenopause" [2]; also we took into account that the mean age in which the menopause occurs among Mexican women is 48 years [23]. Besides the age interval, we also asked postmenopausal candidates the date of the last menstrual period and we only included participants who had their last period no longer than eight years ago. Other inclusion criteria were: at least three visits to the family doctor in the last year; not suffering from type 2 diabetes, hypertension, depression, and/or cancer; being with a stable life partner and agreeing to participate in the study by signing the informed consent.

\section{Study variables}

The dependent variable was HR-QoL, and this was measured with the Cervantes scale [24]. This scale is a specific HR-QoL instrument for menopausal women. The scale has 31 questions and covers four domains: menopause and health, psychological domain, sexuality, and couple relationship. The highest value for the global score is 155 points, which means low HR-QoL, and the lowest value is 0 , which means high HR-QoL.

The independent variable was quality of care, which was measured by ascertaining the percentage of recommended care received [25]. This was estimated for each care process component: health promotion, screening, and treatment (Table 1). It was obtained by calculating a simple proportion, with the sum of indicators that women received as the numerator and the total number of the recommended indicators as the denominator.

The covariates were:

a) Women's general characteristics: Age, schooling, and employment status, which included whether she was involved in paid work.

b) Lifestyle: Healthy diet [26-28] which included the daily consumption of fruits, vegetables, and dairy products, and non-consumption of carbonated beverages; leisure time physical activity (PA) [29] where regular was defined as moderate intensity if done for $\geq 30$ minutes/day $\geq 5$ days/week or vigorous intensity if done three times a week with a duration of 20 minutes per session, irregular was defined as carrying out less than regular PA, or inactivity. Smoking status was focused on current smokers and we registered the number of cigarettes actually smoked per day among those that answered positively. Alcohol consumption was initially classified as non-drinkers (never drink alcohol), occasional drinkers (drink rarely or less than once a week), moderate drinkers (from 1 to 14 drinks per week) and heavy drinkers (more than 14 drinks per week) [30]. It has been reported that moderate alcohol consumption has a positive association with HR-QoL in middle aged women [31]; therefore, we combined non-drinkers and occasional drinkers in a single group and presented the data for moderate alcohol consumption only.

c) Nutritional status was measured by body mass index (BMI) and classified into groups of normal weight (BMI of 18.5-24.9 kg/m ${ }^{2}$ ), overweight (BMI of 25.0 to $\left.29.9 \mathrm{~kg} / \mathrm{m}^{2}\right)$, or obese $\left(B M I \geq 30.0 \mathrm{~kg} / \mathrm{m}^{2}\right)$. d) Social support (SS) was measured by applying the DUKE-UNC-11 questionnaire [32]. This questionnaire evaluates confidential SS (possibility of having people to communicate with) with a minimum score of 7 points (low confidential SS) and a maximum score of 35 points (high confidential SS); and affective SS (demonstration of love, affection, and empathy) with a minimum score of 4 (low affective SS) and a maximum score of 20 points (high affective SS).

e) Medical and reproductive history: Presence of chronic diseases, number of pregnancies and living children, and menopause (one year after the last menstrual period). Type of menopause was classified as natural or surgical, age at onset of menopause; time elapsed since menopause, presence and type of climacteric symptoms, and number of visits with the family doctor in the last year. The severity of vasomotor symptoms and vaginal atrophy symptoms was classified using the criteria proposed by the Department of Health and Human Services Food and Drug Administration [33], which are based upon women's self-report, and define the symptoms as mild, moderate, or severe. f) Satisfaction with care received at the FMC was measured with the general question of how satisfied are you with the care you have received at the FMC? The possible answers were very satisfied, satisfied, neither satisfied nor unsatisfied, unsatisfied, and very unsatisfied.

\section{Sample size}

We estimated a sample size of 400 women to evaluate the possible association between HR-QoL and quality of 
care. The sample size was estimated by using the formula to test the mean of a normal distribution [34]. A mean decrease of at least 5 points on the global Cervantes scale score per $10 \%$ increase in the quality of care received was considered to be clinically relevant. The assumptions included a mean global HR-QoL score of 51.75 points (standard deviation of 23.1 points) [24], $\alpha$ error $=0.05,80 \%$ power, and $10 \%$ of possible nonrespondents (this means that a respondent answered less than $80 \%$ of the questionnaire).

\section{Study description}

In each FMC, the nurse identified candidates in the waiting room, explained the purpose of the study and of the interview, and asked for her signed informed consent. If the candidate agreed to participate, the nurse performed the interview. The questionnaires used during the interview were the Cervantes scale, the DUKEUNC-11 questionnaire, and a structured questionnaire to collect general information and data to measure quality of care.

All questionnaires, including the Cervantes scale, were pretested in 25 women in climacteric stage regarding their understanding of the questions. The supervisory nurse and/or one of the researchers (SVD) reviewed the previous year's clinical notes in the electronic medical record to verify the care that each woman received.

The project was approved by the National Research and Ethics Committee of the IMSS (number 2008-785014).

\section{Statistical analysis}

The descriptive analysis consisted of obtaining measures of central tendency and dispersion for quantitative variables; in the case of categorical variables, absolute and relative frequencies were obtained.

For the descriptive analysis of the HR-QoL, the mean and standard deviation (SD) of global and particular domain scores were obtained. We also categorized HRQoL global score and domain scores into: 1) low HRQoL, severe problem level (+2SD); 2) moderately low HR-QoL, high problem level $(+1 \mathrm{SD}$ and $+2 \mathrm{SD})$; 3 ) regular HR-QoL, low-medium problem level (+1SD and $-1 \mathrm{SD})$; and 4) high HR-QoL, without problems (-1SD) [23]

The association between global HR-QoL score and the percentage of recommended care received for each component of care (health promotion, screening and treatment), as well as for each of the covariates was evaluated through the Spearman correlation test.

To determine the magnitude of the adjusted association between HR-QoL global score and each component of quality of care, we used multiple linear regression analysis. The model included conceptually relevant variables (schooling, confidential and affective support, leisure time physical activity, healthy diet, presence of chronic disease, body mass index, menopause, and satisfaction with health care) that resulted in $\mathrm{p} \leq 0.20$ in the bivariate statistical analysis. The method used for modeling was backwards. The covariate presence/ absence of menopause was included as an adjustment variable and it was not statistically significant, although given its clinical importance it was maintained during the modeling process. It was also tested if menopause influenced the association of interest (relationship between HR-QoL global score and each component of quality of care). The analysis tested the interactions between each component of quality of care and menopause; such interactions were not statistically significant and were not included in the final model.

Once the final model was obtained, the error terms were generated, the assumptions of linearity, normality, and equal variance were tested, and the goodness-of-fit of the regression line was confirmed.

The analysis was performed with the Stata 8.0 statistical software (Stata 8.0, Stata Corp; College Station, TX).

\section{Results}

A total of 424 women met the inclusion criteria, of which $2 \%$ refused to participate due to lack of time to answer the interview questions. Of the 416 women interviewed, 6 (1.4\%) were excluded because they had no medical notes of consultations during the last year in their electronic medical records. The final analysis included 410 women.

\section{General characteristics, lifestyle, nutritional status, and social support (Table 2 )}

The median age was 49 years, and the median schooling was at secondary level. Of the respondents, $64.9 \%$ were devoted to home and had no paid work.

As for lifestyle, the results show that most of women had an unhealthy lifestyle; one in five women reported having a healthy diet, and one in four reported regular physical activity. Only $6.7 \%$ had both a healthy diet and regular leisure time physical activity; $18.3 \%$ were current smokers, they smoked a median of three cigarettes per day. Most of interviewees were non-drinkers or occasional drinkers, only $2 \%$ reported moderate consumption. It was noted that a high proportion of participants were overweight or obese.

On average, the interviewees received moderate social support. The mean score for confidential support was 23.1 on a scale of 7 to 35 points and the mean score for emotional support was 15.5 points on a scale of 4 to 20 points. 
Table 2 General characteristics, lifestyle, nutritional status, and social support

\begin{tabular}{lc}
\hline Variables & $\mathbf{n}=\mathbf{4 1 0}$ \\
& $\mathbf{n}(\%)$ \\
\hline I. General characteristics & \\
Years of age, median (minimum- maximum) & $49(45-59)$ \\
Years of schooling, median (minimum- maximum) & $8(0-20)$ \\
Paid work & $144(35.1)$ \\
II. Lifestyle & \\
Healthy diet & $85(20.7)$ \\
Leisure time physical activity & \\
$\quad$ Regular & $102(24.9)$ \\
$\quad$ Irregular & $67(16.3)$ \\
$\quad$ Inactivity & $241(58.8)$ \\
Current smokers & $75(18.3)$ \\
Number of cigarettes per day, median & $3(1-15)$ \\
(minimum- maximum) & \\
Moderate alcohol intake & $8(2.0)$ \\
III. Nutritional status & \\
Body mass index, kg/m², mean \pm SD & $29.1 \pm 4.3$ \\
$\quad$ Normal weight & $70(17.1)$ \\
$\quad$ Overweight & $189(46.1)$ \\
Obesity & $151(36.8)$ \\
Confidential, mean \pm SD & \\
Affective, mean \pm SD & $23.1 \pm 6.5$ \\
\hline
\end{tabular}

\section{Medical and reproductive history, and climacteric symptoms (Table 3 )}

Half of participating women suffered from one chronic condition, mainly musculoskeletal system diseases (41.9\%), and nutritional and metabolic disorders such as dyslipidemia (19.0\%).

As for reproductive history, the median number of pregnancies and living children was three. Half of the participants were menopausal, of which most had natural menopause. The median age at natural menopause was 49 years and at surgical menopause was 45.5 years; the median time elapsed since menopause was three years. The most frequent climacteric symptoms were changes in the menstrual cycle, hot flashes, sweating, and dyspareunia; very few reported having moderate or severe vasomotor symptoms, with a frequency of 7 or more times a day; $22 \%$ had moderate to severe symptoms of vaginal atrophy. Women attended a median of six visits to their family doctors in the last year.

\section{Quality of care and satisfaction with care (Table 4)}

The quality of care was assessed in three domains: health promotion, screening, and treatment. Regarding health promotion, a low percentage of participants had received counseling about climacteric and menopause, nutrition, leisure time physical activity, and smoking cessation.
The screening component showed important limitations in several components. The family doctor asked about climacteric symptoms in $37.8 \%$ of participants; ascertainment of overweight and obesity were registered in $3.4 \%$, and screening for breast cancer in $42.2 \%$. Hypertension, diabetes, and cervical cancer screening tests were performed in most women $(99.3 \%, 88.3 \%$, and 91.9\%, respectively).

The treatment component indicated that most women had appropriate indication of vaginal and oral HT $(94.6 \%$ and $81.0 \%$, respectively). While $51.6 \%$ of 31 women receiving oral HT had an appropriate prescription in terms of scheme, dose, and time schedule, $38.7 \%$ had received information about the risks and benefits of HT.

The health promotion component had the lowest mean percentage of recommended care $(24.1 \%)$, while the treatment component had the highest (86.6\%). Most of the interviewed women $(64.9 \%)$ reported being satisfied with the care received at the FMC.

\section{Health-related quality of life (Figure 1)}

Women rated their global HR-QoL as follows: high HRQoL, 15.1\%; regular HR-QoL, 67.6\%; moderately low HR-QoL, 13.4\%; and low HR-QoL, 3.9\%. The mean global HR-QoL score was 50.1 points (SD 24.7). The analysis within the domains shows that more women in the couple relationship domain reported high HR-QoL (32.3\%) compared with the other domains; in the sexual domain, nobody reported low HR-QoL.

\section{Relationship between health-related quality of life and quality of care (Table 5)}

The quality of treatment was significantly associated with a better rating of global HR-QoL after adjusting for other variables. The higher mean percentage of recommended care received in the treatment component reduced the mean global HR-QoL score on the Cervantes scale (coefficient $-0.28, \mathrm{P}<0.0001$ ). This means that for each 10 percentage points more of recommended care received in the treatment component, the rate of HR-QoL improved by 2.8 points on the Cervantes scale. The association between HR-QoL and the health promotion and screening components was not statistically significant.

\section{Discussion}

The health of women in the climacteric stage is a complex matter that requires further attention from health services [8]. Some of the health problems that a climacteric woman suffers can be prevented or timely diagnosed, thus allowing the control or mitigation of the potential consequences. Promoting high quality care based on scientific evidence is critical; this helps women to age in better health. 
Table 3 Medical and reproductive history, climacteric symptoms, and number of consultations with family doctor

\begin{tabular}{|c|c|}
\hline Variable & $\begin{array}{l}n=410 \\
n(\%)\end{array}$ \\
\hline \multicolumn{2}{|l|}{ I. Medical and reproductive history } \\
\hline Presence of chronic disease & $202(49.3)$ \\
\hline Number of pregnancies, median (min- max) & $3(1-9)$ \\
\hline Number of living children, median (min- max) & $3(0-9)$ \\
\hline Menopause & $224(54.6)$ \\
\hline Type of menopause & $\mathrm{n}=224$ \\
\hline Natural & $162(72.3)$ \\
\hline Surgical & $62(27.7)$ \\
\hline $\begin{array}{l}\text { Age in which menopause happened, median } \\
\text { (min- } \max \text { ) }\end{array}$ & $n=224$ \\
\hline Natural & $49(38-56)$ \\
\hline Surgical & $45.5(38-53)$ \\
\hline Time elapsed after menopause, years & $3(0-8)$ \\
\hline II. Climacteric symptoms & $\mathrm{n}=410$ \\
\hline Hot flashes & $205(50.0)$ \\
\hline Sweating & $181(44.1)$ \\
\hline Insomnia & $169(41.2)$ \\
\hline Dysuria & $91(22.2)$ \\
\hline \multirow[t]{2}{*}{ Vaginal dryness } & $161(39.3)$ \\
\hline & $\mathrm{n}=186$ \\
\hline \multirow{2}{*}{$\begin{array}{l}\text { Changes in the menstrual cycle in pre-menopause } \\
\text { women }\end{array}$} & $98(52.6)$ \\
\hline & $\mathrm{n}=352$ \\
\hline $\begin{array}{l}\text { Dyspareunia and/or vaginal bleeding in sexual active } \\
\text { women }\end{array}$ & $101(28.7)$ \\
\hline Severity and frequency of vasomotor symptoms & $\mathrm{n}=410$ \\
\hline Absence & $192(46.8)$ \\
\hline Mild & $46(11.2)$ \\
\hline \multicolumn{2}{|l|}{ Moderate } \\
\hline$<7 /$ day & $129(31.5)$ \\
\hline$\geq 7 /$ day & $2(0.5)$ \\
\hline \multicolumn{2}{|l|}{ Severe } \\
\hline$<7 /$ day & $32(7.8)$ \\
\hline$\geq 7 /$ day & $9(2.2)$ \\
\hline Severity of vaginal atrophy symptoms & $\mathrm{n}=410$ \\
\hline Absence & $219(53.4)$ \\
\hline Mild & $101(24.6)$ \\
\hline Moderate & $40(9.8)$ \\
\hline Severe & $50(12.2)$ \\
\hline $\begin{array}{l}\text { III. Number of consultations with a family doctor } \\
\text { during the last year, median (min- } \max \text { ) }\end{array}$ & $6(3-20)$ \\
\hline
\end{tabular}

We designed and validated 14 indicators addressing health promotion, screening, and treatment to assess the quality of the process of care that climacteric stage women receive in family medicine clinics. The indicators should be feasible, available, and continuous. The information for the present study came from two sources: interviews with climacteric stage women and medical records. Combining both sources provided information that is more reliable but increased the cost of data collection since trained personnel was required. In practice, these indicators allowed the analysis of the quality of care process with a swift and replicable methodology.

The evaluation of the quality of care pointed out flaws in the processes of health promotion, screening, and treatment. This finding is similar to the results of other studies reporting that users receive only about half of the recommended actions [35,36].

Health promotion interventions for climacteric stage women include motivation to quit smoking, to follow a healthy diet, and to do regular leisure time physical activity. Carrying out these activities improves their health status, reduces mortality due to chronic diseases, and maintains bone mineral density and muscle strength [26-28,37,38]. Counseling about climacteric stage increases women's knowledge about it and receptiveness about self-care. Informed women can cope better with the physiological and emotional changes that occur at this stage and improve their lifestyle $[39,40]$. In our study, the evaluation of health promotion revealed serious limitations. Only one out of every ten women followed a healthy diet and did regular leisure time physical activity. Most of those with unhealthy lifestyles had not received information to improve it.

In family medicine clinics, all members of the health team should perform health promotion activities: medical doctors, nurses, social workers, nutritionists, etc. Ideally, these activities should be complementary, and the health team members should reinforce them continually. Previous studies performed at IMSS have reported that health promotion is inadequate and requires substantial improvements [41].

Screening of diseases allows timely diagnosis and treatment, thus increasing the probability of better health outcomes. The present study showed that women underwent only half of the recommended screening activities. Screening for overweight/obesity was poor, despite it being easy to perform and the high prevalence of obesity among Mexican women [42]. This finding suggests the need to encourage health services to improve the screening activities and to educate women in this age group to increase the informed demand for preventive care.

During the last years, the appropriate indication and prescription of hormone therapy have been debated [43]. Evidence-based clinical guidelines are available for managing climacteric women. These guides provide recommendations for the indication and appropriate use of hormone therapy, while reducing the risk of adverse events. In our study, we found that the treatment component was close to the current recommendations, but only half of the women were receiving appropriate prescription of oral HT. 


\section{Table 4 Quality of care ${ }^{\dagger}$ and satisfaction with care}

Variable

I. Health promotion

1. Counseling about climacteric and menopause

2. Nutritional counseling

3. Advice on regular leisure time physical activity

4. Smoke cessation counseling in current smokers

\section{Screening}

1. Deliberate search of climacteric symptoms

2. Screening for overweight/obesity

3. Screening for hypertension

4. Screening for diabetes

5. Screening for breast cancer

6. Screening for cervical cancer in women without total hysterectomy

\section{Treatment}

1. Appropriate indication of oral HT

a) Women with moderate or severe vasomotor symptoms $\geq 7 /$ day (at the time of the interview or the time to start oral HT) and without contraindications for HT

oral HT indicated appropriately

oral HT not indicated

b) Women with moderate or severe vasomotor symptoms $<7 /$ day (at the time of the interview or the time to start oral HT), with mild symptoms or without vasomotor symptoms

oral HT indicated

oral HT not indicated appropriately

2. Appropriate indication of vaginal HT

a) women with moderate or severe vaginal atrophy symptoms and without oral HT

vaginal $H T$ indicated appropriately

vaginal HT not indicated

b) women without moderate to severe vaginal atrophy symptoms or with oral HT vaginal $H$ T indicated

vaginal HT not indicated appropriately

Women receiving oral HT

3. Appropriate prescription of oral HT

4. Information on risks and benefits of oral HT

\section{Percentage of recommended care received}

Health promotion

Screening

Treatment

Satisfaction with care received at the FMC

Very satisfied

Satisfied

Neither satisfied nor unsatisfied

Unsatisfied

Very unsatisfied $\mathrm{n}=\mathbf{4 1 0}$

$\mathrm{n}(\%)$

$52(12.7)$

$59(14.4)$

$178(43.4)$

$\mathrm{n}=75$

$23(30.7)$

$$
\mathrm{n}=410
$$

$155(37.8)$

$14(3.4)$

407 (99.3)

$362(88.3)$

$173(42.2)$

$\mathrm{n}=347$

$319(91.9)$

$\mathrm{n}=410$

388 (94.6)

$n=37$

$20(54.0)$

$17(46.0)$

$n=373$

$5(1.4)$

368 (98.6)

332 (81.0)

$\mathrm{n}=87$

9 (10.3)

78 (89.7)

$\mathrm{n}=323$

$0(0.0)$

323 (100.0)

$n=31$

16 (51.6)

$12(38.7)$

$\mathrm{n}=410$

$\%$ mean \pm SD

$24.1 \pm 28.1$

$59.5 \pm 16.8$

$86.6 \pm 22.9$

n (\%)

66 (16.1)

$200(48.8)$

$90(22.0)$

$41(10.0)$

$13(3.2)$

${ }^{\dagger}$ For complete information about the formula of each quality of care indicator, please see Table 1. 
Figure 1. Health-related quality of life measured by Cervantes Scale $(n=410)$

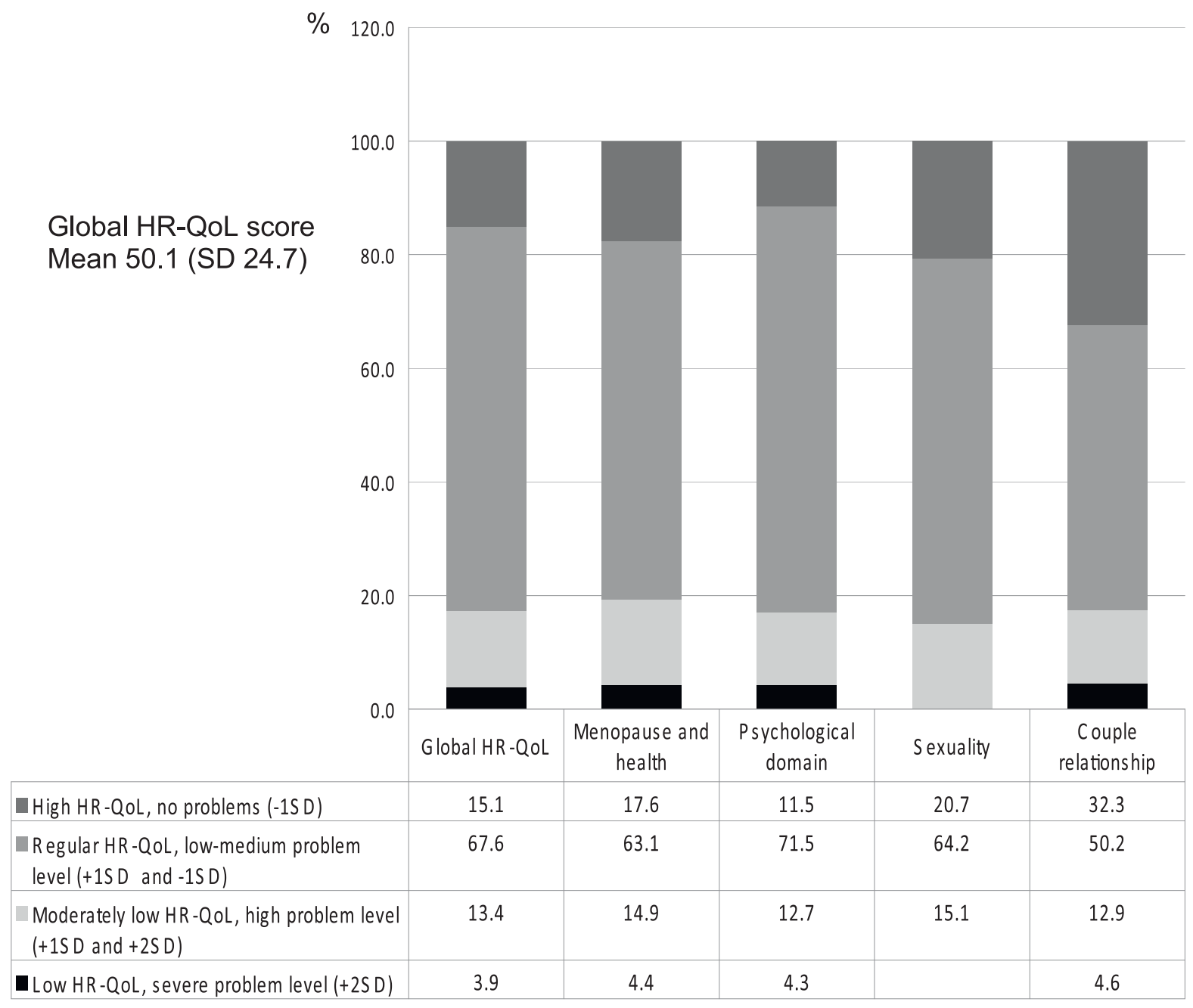

Figure 1 Health-related quality of life measured by Cervantes scale $(n=410)$.

The information/education of women about the purpose, benefits, and potential adverse events of HT contributes to increased adherence to HT and the timely identification of the adverse events. The flaws of the treatment component, such as inappropriate prescription and poor information, stress the need to update the medical staff and to evaluate the quality of care in a continuous way. In addition, it is advisable to search for feasible alternatives to motivate providers to deliver high-quality care. The use of incentives, either in kind or monetary, is a viable approach. In addition, the definition of standards is necessary as this allows the quality to be evaluated in a reliable way; our data would help in defining the standards of care at the local level. The implementation of standards of care and evaluation activities should be tailored to the characteristics of the services that are being evaluated.

In our study, we used the Cervantes scale to measure HR-QoL because this scale comprehensively addresses the main domains of the health of women in climacteric stage. The questionnaire was applied as rigorously as possible, assuring that all participants understood and answered all the questions. In our sample, the mean value for the global HR-QoL score was similar to those reported for Spanish women [24]. It is noticeable that no woman reported severe problems in the 
Table 5 Relationship between health-related quality of life ${ }^{\dagger}$ and quality of care

\begin{tabular}{|c|c|c|c|}
\hline & Coefficient & Confidence intervals at $\mathbf{9 5 \%}$ & $P$ value \\
\hline \multicolumn{4}{|l|}{ Percentage of recommended care received: } \\
\hline Health promotion & -0.01 & $-0.09 ; 0.06$ & 0.722 \\
\hline Screening & -0.09 & $-0.21 ; 0.04$ & 0.158 \\
\hline Treatment & -0.28 & $-0.37 ;-0.19$ & 0.000 \\
\hline Schooling & -1.40 & $-1.98 ;-0.83$ & 0.000 \\
\hline \multicolumn{4}{|l|}{ Leisure time physical activity } \\
\hline Regular & -9.83 & $-14.92 ;-4.76$ & 0.000 \\
\hline Irregular & -6.01 & $-12.04 ; 0.02$ & 0.051 \\
\hline Confidential support & -0.46 & $-0.85 ;-0.07$ & 0.022 \\
\hline Affective support & -1.23 & $-1.93 ;-0.54$ & 0.001 \\
\hline Body mass index & 0.54 & $0.06 ; 1.02$ & 0.027 \\
\hline Absence of menopause & -3.08 & $-7.28 ; 1.05$ & 0.148 \\
\hline Satisfaction with health care in the FMC & -3.72 & $-5.88 ;-1.57$ & 0.001 \\
\hline
\end{tabular}

${ }^{+}$Health-related quality of life measured with the Cervantes scale, where low scores indicate better HR-QoL.

sexuality domain. It is possible that due to sensitive nature of the subject, they were not completely open to answer such question. In another study in Spain that used the Cervantes Scale, it was observed that the answers of women in the sexuality domain were different when they were interviewed directly, than when they answered anonymously the questionnaire. In the open interview they minimized the problems in the sexual domain [44]. In our study, all participants answered to an interviewer. Our findings allow the assumption that the Cervantes scale can be applied to Mexican women but should be validated within the Mexican context.

There is an ongoing trend toward ascertaining the relationship between quality of care and health outcomes $[45,46]$. The present study found that the treatment component was associated with better global HRQoL. This can be due to the effect of the drugs on reducing the climacteric symptoms, thus resulting on improving HR-QoL in the short term; in contrast, the positive effect of the health promotion and screening components would happen in the long term. It is possible that the relationship between these components and HR-QoL is not straightforward. A number of variables intervene, such as changes in lifestyle, women's endowment, etc.

This cross-sectional study has several limitations. It is possible that the evaluation of the quality of care is limited because, in Mexico, the women who use health services often have a chronic illness and require specific attention. In this study, the quality of care assessment was limited to the climacteric stage and did not assess the process of care for other health problems. The study evaluated the quality of care only in IMSS-affiliated women; this affects its external validity. It would be pertinent to consider the applicability of the indicators in other health care institutions. This is reasonable because quality measurements should consider the local conditions. In addition, the probability of misclassifying the indicators for evaluating the appropriate oral and vaginal HT indication exists; each indicator combines two parts 1) appropriate indication for women who need this therapy and 2) no indication for women who do not need it. Because most of the women in the sample do not need to receive either oral or vaginal HT, the results reflect the proper "no indication" more, so the association between HR-QoL and quality of care in the treatment component was probably overestimated. Also, to evaluate the HR-QoL we used the Cervantes scale, which has questions about the couple relationship, which in turn implies that the woman should have a partner. This could represent a limitation in the generalizability of the study, given that it has been reported in Mexico that about $21 \%$ of women of this age do not have a partner [41].

In conclusion, the indicators developed to measure the quality of care process for climacteric stage women are applicable and feasible. Its application in this study showed that health care in this population is limited in the health promotion, screening, and treatment components. There is a positive association between the quality of treatment and HR-QoL, which can encourage the development of interventions aimed at improving the performance of health services. It is advisable to consider the possibility of designing future interventions with a holistic approach toward improving the quality of care for women at this stage.

\section{Acknowledgements}

The authors would like to thank to Dr. Sebastián Carranza Lira, Dr. Manuel Cortes, Dr. José Luis Pozos Cavanzo, Dr. Carlos Duran and Psychologist Jesus Vertiz for their valuable collaboration in designing and validating the quality of care indicators. 
The study was sponsored by the Instituto Mexicano del Seguro Social, grant number FIS/IMSS/PROT/501.

\section{Author details}

${ }^{1}$ Unidad de Investigación Epidemiológica y Servicios de Salud Centro Médico Nacional Siglo XXI, Instituto Mexicano del Seguro Social, México DF, México. ${ }^{2}$ Coordinación de Investigación en Salud, Centro Médico Nacional Siglo XXI, Instituto Mexicano del Seguro Social, México DF, México.

\section{Authors' contributions}

SVD and RPC contributed in conceptualizing the research, data analysis and writing the paper. SFH contributed in the data analysis. LRA contributed in supervising the fieldwork. All authors participated in the interpretation of data, read, and approved the final version of this manuscript.

\section{Competing interests}

The authors declare that they have no competing interests.

Received: 24 November 2009 Accepted: 10 February 2010 Published: 10 February 2010

\section{References}

1. Utian $\mathrm{WH}$ : Ovarian function, therapy-oriented definition of menopause and climacteric. Exp Gerontol 1994, 29:245-251.

2. Menopause and Postmenopause Working Group: Spanish Society of Gynecology and Obstetrics. Spanish Association for the Study of Menopause, Spanish Society of Family and Community Medicine, Iberoamerican Cochrane Centre. Clinical Practice Guideline of Menopause and Postmenopause. Barcelona 2004.

3. Satoh T, Ohashi K: Quality-of-life assessment in community-dwelling, middle-aged, healthy women in Japan. Climacteric 2005, 8:146-153.

4. Guthrie JR, Dennerstein L, Taffe JR, Lehert P, Burger HG: The menopausal transition: a 9-year prospective population-based study. The Melbourne Women's Midlife Health Project. Climacteric 2004, 7:375-389.

5. Utian WH, Janata JW, Kingsberg SA, Patrick LD: Determinants and quantification of quality of life after the menopause: the Utian Menopause Quality of Life score. The Menopause at the Millenium Taylor \& FrancisAso T, Yanaihara T 2000, 141-144.

6. Carey MS, Bacon M, Tu D, Butler L, Bezjak A, Stuart GC: The prognostic effects of performance status and quality of life scores on progressionfree survival and overall survival in advanced ovarian cancer. Gynecol Oncol 2008, 108:100-105.

7. Seid M, Varni JW, Segall D, Kurtin PS: Health related quality of life as a predictor of pediatric healthcare costs: A two-year prospective cohort analysis. Health Qual Life Outcomes 2004, 2:48.

8. Utian WH: Psychosocial and socioeconomic burden of vasomotor symptoms in menopause: a comprehensive review. Health Qual Life Outcomes 2005, 3:47.

9. Schwarz S, Völzke H, Alte D, Schwahn C, Grabe HJ, Hoffmann W, John U, Dören $\mathrm{M}$ : Menopause and determinants of quality of life in women at midlife and beyond: the Study of Health in Pomerania (SHIP). Menopause 2007, 14:123-134.

10. O'Dea I, Hunter MS, Anjos S: Life satisfaction and health-related quality of life (SF-36) of middle-aged men and women. Climateric 1999, 2:131-140.

11. Daley A, Macarthur C, Stokes-Lampard H, McManus R, Wilson S, Mutrie N: Exercise participation, body mass index and health-related quality of life in women of menopausal age. Br J Gen Pract 2007, 57:130-135.

12. Nachtigall LE, Nachtigall MJ: Menopausal changes, quality of life and hormone therapy. Clin Obstet Gynecol 2004, 2:485-488.

13. Koundi KL, Christodoulakos GE, Lambrinoudaki IV, Zervas IM, Spyropoulou A, Fexi P, Sakkas PN, Soldatos CR, Creatsas GC: Quality of life and psychological symptoms in Greek postmenopausal women: association with hormone therapy. Gynecol Endocrinol 2006, 22:660-668.

14. Committee on Quality of Health Care in America: Crossing the Quality Chasm: A new Health System for the 21st Century Washington, D.C: National Academy Press 2001

15. Campbell SM, Roland MO, Buetow SA: Defining quality of care. Soc Sci Med 2000, 51:1611-1625

16. Campbell SM, Braspenning J, Hutchinson A, Marshal MN: Improving the quality of health care. Research methods used in developing and applying quality indicators in primary care. BMJ 2003, 326:816-819.
17. Freeman T: Using performance indicators to improve health care quality on the public sector: a review of the literature. Health Serv Manage Res 2002, 15:126-137.

18. Brook RH, Chassin MR, Fink A, Solomon DH, Kosecoff J, Park RE: A method for the detailed assessment of the appropriateness of medical technologies. Inn J Technol Assess Health Care 1986, 2:53-63.

19. Campbell SM, Hann M, Hacker J, Roland MO: Quality assessment for three common conditions in primary care: validity and reliability of review criteria developed by expert panels for angina, asthma and type 2 diabetes. Qual Saf Health Care 2002, 11:125-130.

20. Saslow D, Runowicz CD, Solomon D, Moscicki AB, Smith RA, Eyre HJ, Cohen C: American Cancer Society Guideline for the Early Detection of Cervical Neoplasia and Cancer. CA Cancer J Clin 2002, 52:342-362.

21. Shekelle PG, MacLean CH, Morton SC, Wenger NS: Assessing care of vulnerable elders: methods for developing quality indicators. Ann Intern Med 2001, 135:647-652.

22. Instituto Mexicano del Seguro Social: Memoria Estadística 2008. México DF 2008. [http://www.imss.gob.mx/estadisticas/financieras/m_est2008cap_2. htm].

23. Malacara JM, Canto de Cetina T, Bassol S, Gonzalez N, Cacique L, VeraRamirez ML, Nava LE: Symptoms at pre- and postmenopause in rural and urban women from three States of Mexico. Maturitas 2002, 43:11-19.

24. Palacios S, Ferrer-Barriendos J, Parrilla JJ, Castelo-Branco C, Manubens M, Alberich X, Marti A y el grupo Cervantes: Calidad de vida relacionada con la salud en la mujer española durante la perimenopausia y posmenopausia. Desarrollo y validación de la Escala Cervantes. Med Clin (Barc) 2004, 122:205-211.

25. Higashi T, Wenger NS, Adams JL, Fung C, Roland M, McGlynn EA, Reeves D, Asch SM, Kerr EA, Shekelle PG: Relationship between number of medical conditions and quality of care. N Engl J Med 2007, 356:2496-2504.

26. AHA Scientific Statement: Diet and lifestyle recommendations revision 2006: a scientific statement from the American Heart Association Nutrition Committee. Circulation 2006, 114:82-96.

27. North American Menopause Society: The role of calcium in peri- and postmenopausal women: 2006 position statement of the North American Menopause Society. Menopause 2006, 13:862-877.

28. Tucker KL, Morita K, Qiao N, Hannan MT, Cupples LA, Kiel DP: Colas, but not other carbonated beverages, are associated with low bone mineral density in older women: The Framingham Osteoporosis Study. Am J Clin Nutr 2006, 84:936-942.

29. Haskell WL, Lee IM, Pate RR, Powell KE, Blair SN, Franklin BA, Macera CA, Heath GW, Thompson PD, Bauman A: Physical activity and public health: Updated recommendations for adults from the American College of Sports Medicine and the American Heart Association. Med Sci Sports Exerc 2007, 39:1423-1434.

30. Clemens SL, Matthews SL, Young AF, Powers JR: Alcohol consumption of Australian women: results from the Australian Longitudinal Study on Women's Health. Drug Alcohol Rev 2007, 26:525-535.

31. Powers JR, Young AF: Longitudinal analysis of alcohol consumption and health of middle-aged women in Australia. Addiction 2008, 103:424-432.

32. Bellón Saameño JA, Delgado Sánchez A, Luna del Castillo JD, Lardelli Claret P: Validez y fiabilidad del cuestionario de apoyo social funcional Duke-UNC-11. Aten Primaria 1996, 18:153-163.

33. U.S. Department of Health and Human Services Food and Drug Administration. Guidance for Industry: Estrogen and Estrogen/Progestin Drug Products to Treat Vasomotor Symptoms and Vulvar and Vaginal Atrophy Symptoms - Recommendations for Clinical Evaluation Center for Drug Evaluation and Research (CDER) 2003http://www.fda.gov/downloads/Drugs/ DrugSafety/InformationbyDrugClass/UCM135338.pdf.

34. Rosner B: Sample size determination. Fundamentals of biostatistics Pacific Grove, Ca: Duxbury RessRosner B , 5 2000, 236-243.

35. McGlynn EA, Asch SM, Adams J, Keesey J, Hicks J, DeCristofaro A, Kerr EA: The quality of health care delivered to adults in the United States. N Engl J Med 2003, 348:2635-2645.

36. Seddon ME, Marshal MN, Campbell SM, Roland MO: Systematic review of studies of quality of clinical care in general practice in the UK, Australia and New Zealand. Qual Health Care 2001, 10:152-158.

37. Eyre $H$, Kahn R, Robertson RM: Preventing cancer, cardiovascular disease and diabetes: a common agenda for the American Cancer Society, the American Diabetes Association and the American Heart Association. CA Cancer J Clin 2004, 54:190-207. 
38. Kohrt WM, Bloomfield SA, Little KD, Nelson ME, Yingling VR: American College of Sports Medicine Position Stand: physical activity and bone health. Med Sci Sports Exerc 2004, 36:1985-1996.

39. Hunter M, O'Dea I: An evaluation of a health education intervention for mid-aged women: Five-year follow-up of effects upon knowledge, impact of menopause and health. Patient Educ Couns 1999, 38:249-255.

40. Jimenez de Luque MP, Serrano Monzó I, Sabaté Baruque I, Satrústegui Sáez B, Azcona Montero C: Health education during menopause. A longrange evaluation. Rev Enferm 2000, 23:26-31.

41. Vladislavovna-Doubova S, Pérez-Cuevas R, Reyes- Morales H: Self-rated health among climacteric women affiliated to Instituto Mexicano del Seguro Social. Salud Publica Mex 2008, 50:390-396.

42. Flores-Huerta S, Acosta-Cázares B, Gutiérrez-Trujillo G: ENCOPREVENIMSS 2003. Prevalence of low weight, overweight, general obesity and central obesity. Rev Med Inst Mex Seguro Soc 2006, 44:55-62.

43. Shapiro S: Recent epidemiological evidence relevant to the clinical management of the menopause. Climateric 2007, 10:2-15.

44. Castelo-Branco C, Palacios S, Ferrer-Barriendos J, Alberich X, the Cervantes Study Group: Do Patients Lie? An Open Interview vs. a Blind Questionnaire on Sexuality. J Sex Med 2009.

45. Higashi T, Shekelle PG, Adams JL, Kamberg CJ, Roth CP, Solomon DH, Reuben DB, Chiang L, MacLean CH, Chang JT, Young RT, Saliba DM, Wenger NS: Quality of care is associated with survival in vulnerable older patients. Ann Intern Med 2005, 143:274-281.

46. Hanlon JT, Fillenbaum GG, Kuchibhatla M, Artz MB, Boult C, Gross CR, Garrard J, Schmader KE: Impact of inappropriate drug use on mortality and functional status in representative community dwelling elders. Med Care 2002, 40:166-176.

doi:10.1186/1477-7525-8-20

Cite this article as: Doubova Dubova et al:: Quality of care and healthrelated quality of life of climacteric stage women cared for in family medicine clinics in Mexico. Health and Quality of Life Outcomes 2010 8:20.

\section{Submit your next manuscript to BioMed Central and take full advantage of:}

- Convenient online submission

- Thorough peer review

- No space constraints or color figure charges

- Immediate publication on acceptance

- Inclusion in PubMed, CAS, Scopus and Google Scholar

- Research which is freely available for redistribution

Submit your manuscript at www.biomedcentral.com/submit
Biomed Central 